$\begin{array}{ll}\text { Research Square } & \text { Preprints are preliminary reports that have not undergone peer review. } \\ \text { They should not be considered conclusive, used to inform clinical practice, } \\ \text { or referenced by the media as validated information. }\end{array}$

\title{
A Study on the Relationship Between Smoking Reasons Evaluation and Smoking Cessation Attempt of Smokers - Based on a Cross-sectional Survey in Beijing's Community
}

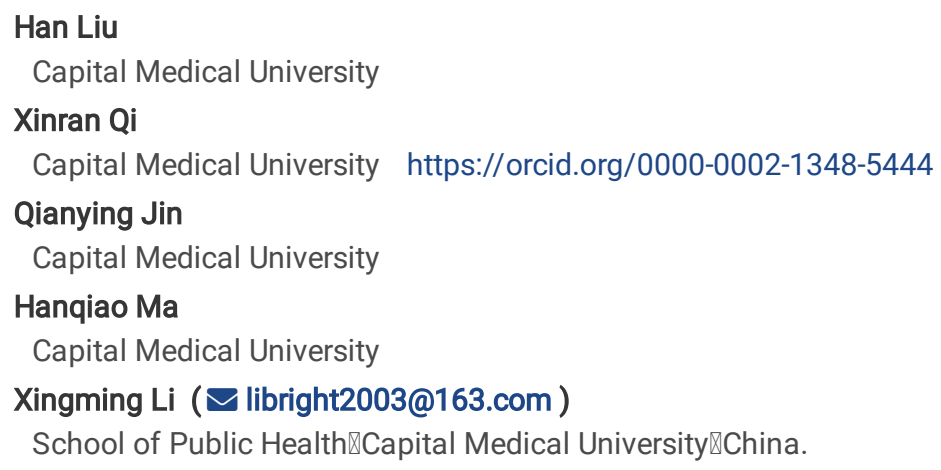

\section{Research article}

Keywords: Tobacco dependence, Reason for smoking, Smoking cessation behavior, Quit attempt

Posted Date: August 28th, 2020

DOI: https://doi.org/10.21203/rs.3.rs-48083/v1

License: (1) This work is licensed under a Creative Commons Attribution 4.0 International License. Read Full License 


\section{Abstract}

\section{Background》}

The reason for smoking causes people to smoke in their daily life. It is the main factor hindering the success of quitting smoking. This study analyzed the differences and characteristics of tobacco dependence patients with different smoking causes in their past smoking cessation behaviors, to understand the relationship between smoking cessation behaviors and smoking causes, and provide a reference for the innovation of the tobacco dependence management model.

\section{Methods $\rrbracket$}

Based on a cross-sectional epidemiological study, a total of tobacco dependence patients over 18 years old to quit smoking were recruited from various communities in Beijing. The survey included basic demographic information, tobacco use, attempts to quit, reasons for smoking, etc. Analysis of variance and dichotomous Logistic Regression was used to investigate the relationship between smoking causes and smoking cessation behaviors and their duration.

\section{Results】}

A total of 673 participants were recruited, including 611 males (90.8\%), 428 smokers (63.6\%) and 245 males (36.4\%) who tried to quit smoking. ANOVA was used to find that the attempts to quit smoking were statistically correlated with scores of sedation, stimulation, smoking addiction, and automatism (all $p<0.05)$. Sedation (OR=1.111, 95\% Cl: 1.011-1.220), smoking addiction, (OR=1.152, 95\%Cl: 1.034-1.282) and automatism $(\mathrm{OR}=1.119,95 \% \mathrm{Cl}: 1.000 \sim 1.251)$ were found statistically related the attempts to quit smoking by the Logistic regression model. The mean scores of hand and mouth activity, hedonic sedation, stimulation, smoking addiction, and auxiliary factors were statistically significant in different smoking cessation duration groups (all $p<0.05$ ), and sedative factors were negatively related factors for smoking cessation duration (OR=0.911, 95\% Cl: 0.827-1.002).

\section{Conclusion】}

Most residents try to quit smoking only when they are heavily physiologically dependent or even physically unwell. The success or failure of smoking cessation is closely related to social psychology and physical dependence. Most smokers only try to quit by their own will without professional help. Lack of a supportive environment and other people's understanding is a major cause of smoking cessation failure. Creating a smoke-free supportive environment should be an important part of community tobacco control and smoking cessation efforts.

Fund program: Supported by the Foundation of National Key R\&D Program of China (2017YFC1309400)

\section{Background}

Smoking seriously harms people's health. As the country with the largest number of smokers in the world ${ }^{[1]}$, China now has more than 300 million smokers, and the smoking rate of the population aged 15 and above is roughly $26.6 \%{ }^{[2]}$. Quitting smoking is the only way for smokers to get rid of the harm of tobacco dependence $₫$ which is well-known as a chronic disease (ICD-10, F17.2), nicotine in tobacco can lead to a strong physical dependence and psychological dependence, prompting patients compulsively, continuous use of tobacco to experience euphoria and pleasure from it, and to avoid possible withdrawal symptoms, thus quit smoking process is an easily repeated and rough period. Attempts to quit smoking are the prerequisite for successful smoking cessation. The frequency and duration of quitting smoking will influence the awareness of quitting smoking, the success rate of quitting smoking, and the attitude and effectiveness of smokers towards intervention ${ }^{[3-4]}$. The reasons for smoking cause the promotion of People's Daily smoking behavior as well as the main factors hindering the success of smoking cessation. The reasons for people to smoke are various, which are influenced by multiple factors of individual physiology, psychology, and social environment, and there are obvious individual differences ${ }^{[5-6]}$. Domestic and foreign scholars mainly use Russell's questionnaire on the reasons for smoking to investigate the reasons for smoking in the population, and study the relationship between it and the population's social psychology, personality characteristics and tobacco dependence, to put forward corresponding prevention measures and tobacco control measures ${ }^{[7-8]}$. In this study we aimed at exploring the relationship between smoking causes and smoking cessation behaviors, analyzing the differences and characteristics of tobacco dependence patients with different smoking causes in their smoking cessation behaviors, as well as providing a theoretical basis for providing better help for smoking cessation, optimizing tobacco dependence management mode, and supporting environment for smoking cessation.

\section{Methods}

\section{Study design and participants}


Our research was based on an epidemiological cross-sectional study design. Data from the survey of community healthcare institutions and agencies in Beijing, 2018 were analyzed. This representative study was certified by the Medical Ethics Committee of Capital Medical University (No. Z2019SY007) and registered in the Chinese Clinical Trial Registry (No. ChiCTR1900024991), one of the largest clinical trial register organization.

Samples who were willing to participate in a community intervention project of tobacco dependence patients were selected by multi-stage sampling as investigation objections. Well-trained health investigators administered laptop-based questionnaires at local study clinics and agencies to collect the following information:

(1)Socio-economic and demographic factors: age, sex, education level, marital status, occupation, monthly income, etc.

(2)Tobacco use: nicotine dependence score, smoking age and the age of start smoking, etc.

Nicotine Dependence scale: The Fagerstrom Test of Dependence (FTND) is used. This scale consists of 6 items. Each item is scored on a scale of 0-3, indicating the lightest Dependence to the most dependent. The degree of nicotine dependence was judged by the total score of 6 items, which was divided into 0 2 points = very low; $3 \sim 4$ points = low; 5 points = medium; $6 \sim 7$ points $=$ high; The Cronbach's coefficient of the Chinese version of nicotine dependence scale was 0.658 , indicating good internal consistency ${ }^{[10]}$.

(3)Cessation history: try to quit smoking behavior (try to quit smoking for the sake of long-term smoking behavior and to rid of $24 \mathrm{~h}$ or more) [11], quit smoking duration (especially the last time this study attempts to quit smoking, the duration of the stop smoking), quit smoking methods (for topic selection, set consulting, nicotine replacement, Chinese herbal medicine/acupuncture, dry up nine options), relapse reasons (for topic selection, set up self-perseverance, lack of professional guidance, lack of support smoke-free environment, lack of understanding others and so on 10 option), etc.

(4)Smoking reasons (through Russell "Reason for Smoking Questionnaire, RRSQ ${ }^{[12]}$ ).

RRSQ scale is composed of 24 items ${ }^{[13]}$, a total of eight factors can be divided into two dimensions, each entry under" not sure or not ", "sometimes", "have" and "often" assignment $1 \sim 4$ points respectively; The reliability test of the survey results showed that the overall Cronbach's coefficient was 0.903 , the dimensions of social psychology and dependency addiction were 0.729 and 0.878 respectively, and the subscales of

all factors were above 0.6 except hand and mouth activity, showing good internal consistency ${ }^{[14]}$. The meanings of RRSQ factors are as follows: I. Mental imagery: High scores are common among young people who have just started smoking, especially teenagers, who consider smoking a fashion, a sign of manhood, poise, sophistication, maturity, etc. II. Mouth and hand activity: score high feel smoking is to have a kind of thing in the hand in the mouth, is a habit of action, we can hear the smoker often say not smoking as if there is no place to put the hand, mouth no taste. III. Pleasure: People with high scores often smoke as a means to increase their positive mood, and feel that smoking is a comfortable and leisurely thing. IV. Sedation: People with high scores often use smoking as a means to reduce negative emotions, such as stress, anxiety, or stressful events, which are the most common reasons for smoking. V. Stimulation: high scores often smoke as a means to improve cerebral cortex excitability, often in the need to pay attention to mental work after fatigue smoking. VI. Addiction: High scores indicate addiction to nicotine, at least psychologically, and especially cravings for it. Automatic: A high score indicates that a smoker's smoking behavior is sometimes automatic and unconscious, such as lighting up before he or she is aware of smoking, and is a sign of dependence.

The survey received 693 completed responses in total. Respondents who entered our final analyses were limited to those (1) who signed informed consent, (2) at the age of 18 and above, and in line with the diagnostic criteria ${ }^{[9]}$ tobacco dependence; (3) were permanent residents of the community and (4) were able to answer all investigated questions and submitted without basic logic errors. To ensure without the logical errors, we rechecked the quality of answers and excluded the samples with poor quality. After applying these inclusion criteria, individual data of 673 respondents were used in the present analysis.

\section{Statistical analysis}

Descriptive analyses were used to illustrate the basic demographic, socioeconomic, and lifestyle characteristics in different smoking consumption and cessation groups. Continuous variable was reported as the mean and standard deviation (SD) while categorical variables were described as percentages. Differences in sociodemographic characteristics were assessed using Fisher's exact test and $\chi 2$-tests. Analysis of variance (ANOVA) was used for the intergroup comparison of the scores of RRSQ for smoking reasons and the duration of smoking cessation. Multiple logistic regression was used to assess the associations between smoking reasons and smoking cessation behaviors stratified by sex, $\mathrm{P}<0.05$ was considered statistically significant. Odds Ratio (OR) and $95 \%$ confidence intervals ( $95 \% \mathrm{Cl}$ ) were calculated to indicate the extent of association between the exposure and outcome variables. All data analyses were from the database constructed by Epidata v.3.1 and conducted under SPSS 22.0.

\section{Results}


Among all 673 participants, $90.8 \%$ were male smokers. Among them, the proportion of males aged $60-69$ was $32.4 \%$. 584 (86.8\%) were married; $358(53.2 \%)$ had a high school diploma; In terms of working status, 288 people have been retired (42.8\%), and 271 people (40.3\%) have a monthly income between 2,001 and 4,000 yuan. The self-rated health status was moderate or good at most (297 (44.1\%) and 268 (39.8\%), respectively). In addition to the monthly income levels, there was no statistical difference in the distribution of other demographic variables $(p>0.05)$ between the subjects who had tried to give up smoking and those who had not $(p>0.05)$. With the increase of the monthly income level, the rate of trying to give up smoking increased.

Since all the smokers included in this survey have some intention to quit at this stage, most of the respondents have tried to quit smoking, and $428(63.6 \%)$ have tried to quit in the past. 334 people said they had started smoking before the age of 20 (49.6\%), and a total of 290 had smoked for more than 40 years (43.1\%). In terms of nicotine dependence, 188 people were "very low" (27.9\%) and 159 people were "high" (23.6\%). There was no significant difference in the distribution of tobacco use among those who had tried to give up smoking $(P>, 0.05)$ in the test of chisquare, as shown in Table 1.

Of the 428 respondents who had tried to quit smoking, 146 had tried to quit smoking only once (34.1\%) and 133 had tried to quit smoking twice (31.3\%). The smoking cessation duration ranged from 1 to 7 days (27.1\%), and 113 lasted for more than 1 month, but less than 6 months (26.4\%), as shown in Table 4. Further investigate the process of their attempt to quit smoking, look from the way, the vast majority of respondents have not accepted the professional quit smoking help before, nearly eighty percent of the respondents only past smoking behavior is relying on personal perseverance to dry (78.7\%), often with the help of any drug and psychological intervention, and only 30 people answer related consultation (7.0\%) was conducted. They also attributed their failure to quit to uncontrollable cravings and lack of willpower (56.3\%). Another $35.7 \%$ cited the influence of other smokers as a major factor in their failure to quit.

The relationship between smoking causes and attempted smoking cessation behaviors and their duration as follows:

(1) Try to quit smoking: The results of variance analysis showed that the scores of the four factors including sedation, stimulation, smoking addiction, and automaticity of the subjects who had tried to quit smoking were significantly different from those of the residents who had not tried to quit smoking, and the average scores were slightly higher than those of the residents who had not tried to quit smoking ( $F=14.509,7.945$, 11.636ه8.217, respectively, $p<0.05)$. Meanwhile, the overall mean score of addiction dependence dimension was also higher than that of the residents who had not tried to quit smoking, with statistically significant difference ( $F=14.694, p<0.05)$, suggesting that the patients who had tried to quit smoking might have a higher degree of tobacco dependence addiction, which reflected their difficulties in quitting smoking in the past. There was no statistically significant difference in the average score between the two groups in the social-psychological dimension ( $p>0.05$ ).

Logistic regression further suggested the regression relationship between various smoking causes of RRSQ and smoking cessation behaviors except for the influence of confounding factors such as age and monthly income. The results showed that the regression coefficients of sedation, smoking addiction, and automatism were statistically significant (all $p<0.05$ ). All the three factors were risk factors for smoking cessation, among which the probability of trying to quit increased by 1.111 times for every 1 point increase in sedative factor score, the probability of trying to quit increased by 1.152 times for every 1 point increase in smoking addiction factor score, and the probability of trying to quit increased by 1.119 times for every 1 point increase in automatic factor score. The regression coefficients of age, monthly income, and other confounding factors were not statistically significant (all $p>0.05$ ), as shown in Table 3 and Table 4.

(2) Duration of smoking cessation attempts:

Further discussed in the process of trying to quit smoking behavior quit smoking duration and smoking cause relations, in 428 there was trying to quit smoking behavior of the respondents, addiction in dimensions, hand mouth activity, hedonic scores of two factors in different duration of smoking cessation differences statistically significant $(F=3.215,4.424, p<0.05)$, with the extension of duration, the score gradually reduce; In the social-psychological dimension, the scores of sedation, stimulation, smoking addiction and assistance were statistically different ( $F=6.642$, $4.376,5.844 \llbracket 6.852$ respectively, $p<0.05)$, and the changing trend of scores was similar to that of the social-psychological dimension. The results suggest that both psychosocial and tobacco dependence are important factors affecting smoking cessation behavior and its duration, and psychological, mental, and physiological dependence may hinder smoking cessation success.

Under the Logistic regression model, the regression coefficient of the sedative factor in the addiction dimension was statistically significant $(p<0.05)$, which was a negatively related factor for the time of trying to quit smoking. For every 1-point increase in sedative factor, the probability of the duration of quitting smoking is increased by one level was 0.911 times as high as before. Although the other factor coefficients were not statistically significant, they were generally negative, suggesting that hand and mouth activity, enjoyment, stimulation, smoking addiction, and automaticity were all protective factors for the maintenance time of smoking cessation, as shown in Table 4 . The results of smoking cessation behavior and its duration suggest that in fact, people often wait for a high degree of tobacco dependence before trying to quit, but during the process of quitting smoking, they cannot keep abstinence for a long time due to the social-psychological factors and high dependence addiction, and finally end up with failure to relapse. As shown in Table 3 and Table 4.

Page $4 / 13$ 


\section{Discussion}

Tobacco use is the leading preventable cause of death worldwide, causing nearly 6 million deaths and hundreds of billions of dollars of economic losses every year. Quitting smoking is the only effective way to help tobacco-dependent patients get rid of the harm of smoking ${ }^{[15]}$. At present, the willingness and the success rate (the relapse rate is $90 \% \sim 95 \%{ }^{[16-17]}$ ) for smokers to quit smoking is generally low in China since they were difficulty quitting smoking without help. To investigate the past smoking cessation behavior of tobacco-dependent patients and its relationship with the causes of smoking, analyze the key factors affecting the success of smoking cessation, and provide references for supporters to better provide help for smoking cessation.

In this survey, residents who had tried to quit smoking were higher than the results of the national adult tobacco survey since one of the purposes of this study is to provide a reference for exploring grassroots smoking cessation intervention, so the residents involved are willing to cooperate and have a certain willingness to quit smoking. In this study, the possibility of trying to quit smoking increases with the increase of monthly income levels. On the one hand, it indicates that economic factors influence people's attitude towards quitting smoking, and on the other hand, it also indicates that residents with different occupational status and life status have different pursuit of a healthy lifestyle for themselves and their families. In addition, the percentage of people who tried to quite increased with the decline in self-reported health status, suggesting that physical causes were an important factor in quitting behavior. Many tobacco-dependent patients do not start to quit smoking until they have abnormal symptoms and are reminded or even required by doctors ${ }^{[18]}$.

RRSQ smoking causes scale, calm, stimulation, addiction, automatic and trying to quit smoking behavior is closely related to the four factors such as, divide residents tried to quit smoking is significantly higher than did not try, with calm, smoke, automatic three factors by Logistic regression, is to stop smoking behavior risk factors, it also illustrates the smokers trying to quit smoking has formed a higher degree of dependence and addiction, they or the smoking as a means to reduce the negative emotions, to alleviate tension and anxiety; Or as a stimulant to stimulate the brain to concentrate; Additionally, smoking for them is already a kind of involuntary behavior, in both physical and mental dependence. It is more complicated for patients to quit smoking when they are not feeling well or being aware of their dependence. On the other hand, smokers with a lower degree of dependence are less likely to try to quit. They are not aware of the dangers of tobacco dependence and its related complications. Most of them have no clear understanding of the relevant knowledge and believe that they are not too addicted冈and can be regarded as the "moderate" level. Just like whether low tar and low nicotine are less harmful, it is a common misconception in people's lives. A small amount of smoking does not mean that it can reduce the incidence of cardiovascular disease and lung cancer. The real effective method is to completely quit smoking ${ }^{[19-20]}$.

In the process of trying to quit smoking, the scores of social-psychological factors such as hand activity and pleasure were significantly different among the subjects with different smoking cessation durations, and the average scores increased and decreased with the duration. This suggests that when subjects use smoking as a habitual activity or as a way to increase positive emotions for pleasure, they are less likely to persist in long-term abstinence and have an increased risk of relapse, suggesting that psychosocial factors are also key to smoking cessation. In the process of quitting smoking, it is often more difficult to get rid of psychological dependence than physical dependence. Given the chronic and highly recurrent characteristics of tobacco dependence, continuous psychological support, and advice during quitting smoking are particularly important ${ }^{[3]}$. Also, with the increase of the duration of smoking cessation, the mean score of the four factors of dependence addiction - sedation, stimulation, addiction, and automatization - also presented an increasing trend. Among them, the sedation factor was used as a negatively related factor for the duration of smoking cessation in the regression model, indicating that patients with a lower degree of dependence addiction stopped smoking for a longer time. Previous studies have shown that the level of anxiety and depression in tobaccodependent patients is generally higher than the general population, and these negative psychological effects have a stronger influence on relapse than positive psychological effects. For patients with high dependence, although they know the harm of smoking on individual psychology and physiology, they still use it as a means to relieve negative emotions and concentrate, thus falling into a vicious circle. In this survey, many patients do not have a high degree of nicotine dependence at present, but they still show difficulty in giving up cigarettes and start smoking again after quitting smoking for a while, which may be caused by the interaction between physiological dependence and psychological dependence ${ }^{[21-22]}$. Therefore, quitting smoking requires the intervention of multiple means including drug, psychological, and social support, and quitters should also make it clear that quitting smoking itself is a repeated and long-term process. Most smokers have relapse experience and should not lose confidence due to one failure.

In terms of smoking cessation methods, nearly 80 percent of people in the study used to quit based on personal willpower, only a small number of patients have had any form of professional counseling. Among them, less than $1 \%$ have called the smoking cessation hotline. Some of them have never heard of the smoking cessation service hotline and the smoking cessation clinic. In line with the smoking causes survey, the majority of smokers who tried to quit also attributed their relapse to uncontrollable cravings, a lack of professional guidance, a smoke-free supportive environment, and exposure to other smokers. To reveal the need for scientific and professional help in smoking cessation, and the significance of other people's and external smoking cessation support environment for individuals' success in smoking cessation. 
Based on the above discussion, this study found that the management of tobacco dependence at the grassroots level in China faces the following three major problems: Firstly, residents' awareness of and attention to the harm of tobacco dependence needs to be further strengthened, and most residents do not try to quit smoking until they are severely physiotherapy or even physically unfit. Due to this problem, health popularization should be strengthened, health knowledge should be spread through various forms, smoking cessation should be encouraged in time, and residents should be more aware of the concept of "early smoking, early benefit". Secondly, the success of smoking cessation is closely related to psychosocial and physical dependence, and the vast majority of smokers who try to quit only rely on their own will and lack professional help. It is suggested that the community explore the linkage mode with smoking cessation clinics in general hospitals. Tobacco dependence requires more professional and continuous psychological and spiritual counseling and even drug treatment. Regular follow-up and timely advice should be given according to personal conditions. Grassroots communities can participate in the comprehensive management by training community doctors, organizing follow-up visits, recommending or referring patients to smoking cessation clinics, etc. Thirdly, the lack of a supportive environment and other people's understanding is a major cause of smoking cessation failure. Creating a smokefree environment is an important part of community tobacco control and smoking cessation efforts. The concept of green smoke-free smoking should be advocated from the street to the community and even to residential buildings. Posting smoke-free signs in public places to strictly control smoking; Set up a community volunteer team to actively persuade smokers and pass on knowledge and concepts related to smoking cessation; Set up a smoke-free family model, carry out parent-child activities, public lectures, etc., to create a supportive atmosphere for smokers to quit.

\section{Conclusion}

In conclusion $₫$ most residents do not try to quit smoking until they are severely physiologically dependent or getting sickness; Whether they quit smoking successfully is significantly related to the psychosocial and physiological dependence factors of smoking. Most of those who try to quit smoking only rely on their own will. Thus, lack of a supportive environment and the comprehension of others is a crucial reason for their failure of smoking cessation. It is necessary to strengthen people's awareness of the harm of tobacco through health popularization, and promote the construction of community smoking cessation clinics, as well as popularizing the professional help for smoking cessation. Meanwhile, a smoke-free supporting environment also should be built as an essential part of community tobacco control on smoking cessation project soon.

\section{Abbreviations}

RRSQ Russell Reason for Smoking Questionnaire

FTND®Fagerstrom Test for Nicotine Dependence

\section{Declarations}

\section{Ethics approval and consent to participate}

This study has been certified by the Medical Ethics Committee of Capital Medical University (No. Z2019SY007), and the informed consent has been signed with all the subjects before the investigation.

This study has been registered on the official website of China Clinical Trial Registry, name: Search for Optimization of Tobacco Dependence Management Model Based on Hospital and Community (No. ChiCTR1900024991).

\section{Consent to publish}

All authors declare that they agree to publish the paper.

\section{Availability of data and materials}

The datasets generated and analyzed during the current study are not publicly available, but are available from the corresponding author on reasonable request. The data we used in this study were collected by the authors through community investigation, the subject has not been completed and the data have not been published at present.

\section{Competing interests}

The authors declare that they have no competing interests.

\section{Funding}


The study was supported by the Foundation of National Key R\&D Program of China (2017YFC1309400)

\section{Authors' Contributions}

$\mathrm{XL}$ is charged with the study design, conceptualized the ideas, and supervised the whole analytical procedure. HL participated in the study design, organized community survey, and was a major contributor in writing the manuscript. XQ participated in the Article writing. QI, HM, and KQ participated in the data collection. All authors read and approved the final manuscript.

\section{Acknowledgments}

We appreciate all 673 respondents who participated in this survey. And we would also give thanks to the staff of the communities' management agency who have helped us with this survey.

\section{References}

1. Ministry of Health of the People's Republic of China. Report on the Health Hazards of Smoking in China. Beijing, 2012 [EB/OL]. [2020-120].http://www.gov.cn/jrzg/2012-05/31/content_2149305.htm

2. Tobacco Control Office of The Chinese Center for Disease Control and Prevention. Results of the 2018 Chinese Adult Tobacco Survey [EB/OL]. [2020-1-20].

3. http://www.chinacdc.cn/yw_9324/201905/t20190530_202932.html.

4. Yang G L, Xu Y, Chen L, et al. Current status and influencing factors of smoking cessation among smokers in some urban and rural areas of Wenzhou [J]. Chinese Journal of Health Management, 2016, 10(2): 105-111.

5. DOI: $10.3760 / \mathrm{cma}$. j. issn. 1674-0815.2016.02.006.

6. Siahpush M, Mcneill A, Borland R, et al. Socioeconomic variations in nicotine dependence, self-efficacy, and intention to quit across four countries: findings from the International Tobacco Control (ITC) Four Country Survey [J]. Tob Control, 2006, 15 Suppl 3: iii71-75. DOI: $10.1136 /$ tc. 2004.008763 .

7. Stanaway RG , Watson DW. Smoking motivation: A factor-analytical study[J]. Personality and Individual Differences, 1980, 1(4):371-380.

8. Shi Baolin, Zhao Qiuzhen, Wang Junming, et al. Typical Correlation analysis between smoking causes and personality characteristics of medical students [J]. Chinese School Health, 2011(06):75-76.

9. McManus IC, Weeks SJ. Smoking, personality and reasons for smoking[J]. Psychological Medicine, 1982, 12(2):349-356.

10. Han Mingkui, Zhou Yunping, Li Suyun. Analysis on the relationship between smoking causes and successful smoking cessation [J]. Chinese journal of epidemiology, 2014,35 (10):1083-1086.

11. National Health and Family Planning Commission of the People's Republic of China. Chinese Clinical Guidelines for Smoking Cessation (2015 edition)[J]. Health Care for the Elderly, 2015, 10(8):88-95.

12. HEATHERTON,T. The Fagerstrom Test For Nicotine Dependence, a revision of the Fagerstrom Tolerance Questionnarire[J]. Br J Addict, 1991, 86(9):1119-1127.

13. Jones DN, Schroeder JR, Moolchan ET. Time spent with friends who smoke and quit attempts among teen-smokers[J]. Addict Behav, 2004, 29(4): 723-729.

14. Hedwig Boudrez, Dirk De Bacquer. A Dutch version of the Modified Reasons for Smoking Scale: factorial structure, reliability and validity[J]. Journal of Evaluation in Clinical Practice, 18(4):799-806.

15. Wang X. Handbook of Mental Health Rating Scale [M]. Beijing: China Journal of Mental Health.1999.318-319.

16. Ma Wenjun, Pan Bo. Reliability and validity of the questionnaire and how to analyze it with SAS software [J]. China health statistics, 2000 , 17 (6): 364-365.

17. WHO report on the global tobacco epidemic, 2019:Offer help to quit tobacco use[R].

18. https://www.who.int/tobacco/global_report/en/

19. Chinese Center for Disease Control and Prevention. Survey Report of The International Tobacco Control Policy Assessment Program in China from the first round to the fifth round (2006-2015).2017. http://www.chinacdc.cn/jkzt/jkcj/sthd_3844/slhd_4156/201706/t20170601_143687.html

20. Xiao D, Wang Chen. Prevention of relapse among quitters [J]. Chinese Journal of General Practitioners, 2009, 08(6):368-368.

21. Liu L X, Yang Y, WANG J J, et al. Study on the attempted cessation rate of Adult Smokers in China and its influencing factors [J]. Chinese Journal of Health Education, 2018, V. 34(05):5-8.

22. Wang F M, Zhao J B, Yang L T, et al. Relationship between smoking, alcohol consumption and diabetes among community residents [J]. Chinese Journal of Disease Control, 2008, 12(2):103-106. 
23. Li Xingming, Cui Xiaobo, Zou Mengxuan, et al. Investigation on the Cognition of Beijing residents aged 18 and over on the harm of Low-tar cigarettes [J]. China Health Education, 2013(11):23-26.

24. Zvolensky MJ囚Stewart SH囚Vujanovic AA囚et al. Anxiety sensitivity and anxiety and depressive symptoms in the prediction of early smoking lapse and relapse during smoking cessation treatment[J]. Nicotine Tob Res.2009.11(3):323-331.

25. Brown RA, Kahler CW, Zvolensky MJ, et al. Anxiety sensitivity $\bigotimes$ relationship to negative affect smoking and smoking cessation in smokers with past major depressive disorder囚J囚. Addict Behav囚26(6):887-899.

\section{Tables}

Table 1 The description of socio-demographic characteristics among respondents and the cessation attempts distribution in the two groups in Beijing China, 2018-2019N=673ם[n(\%)] 


\begin{tabular}{|c|c|c|c|c|c|c|c|}
\hline \multirow[t]{2}{*}{ Characteristic } & \multicolumn{2}{|c|}{ Overall( $(n=673)$} & \multicolumn{4}{|c|}{ Whether had Smoking cessation attempts or not } & \multirow[t]{2}{*}{ p-value } \\
\hline & & & \multicolumn{2}{|c|}{ Yes(n1=428) } & \multicolumn{2}{|c|}{ No(n2=245) } & \\
\hline \multicolumn{8}{|l|}{ The basic information } \\
\hline \multicolumn{8}{|l|}{ Gender } \\
\hline male & 611 & $(90.8)$ & 394 & $(64.5)$ & 217 & $(35.5)$ & 0.133 \\
\hline female & 62 & $(9.2)$ & 34 & $(54.8)$ & 28 & $(45.2)$ & \\
\hline \multicolumn{8}{|l|}{ Age(years) } \\
\hline $19 \sim$ & 23 & $(3.4)$ & 13 & $(56.5)$ & 10 & $(43.5)$ & 0.631 \\
\hline $30 \sim$ & 82 & $(12.2)$ & 55 & $(67.1)$ & 27 & $(32.9)$ & \\
\hline 40 & 98 & $(14.6)$ & 63 & $(64.3)$ & 35 & $(35.7)$ & \\
\hline $50 \sim$ & 200 & $(29.7)$ & 124 & $(62.0)$ & 76 & $(38.0)$ & \\
\hline $60 \sim$ & 218 & $(32.4)$ & 135 & $(61.9)$ & 83 & $(38.1)$ & \\
\hline $70 \sim$ & 52 & $(7.7)$ & 38 & $(73.1)$ & 14 & $(26.9)$ & \\
\hline \multicolumn{8}{|l|}{ Marital status } \\
\hline married & 584 & $(86.8)$ & 377 & $(64.6)$ & 207 & $(35.4)$ & 0.185 \\
\hline other & 89 & $(13.2)$ & 51 & $(57.3)$ & 38 & $(42.7)$ & \\
\hline \multicolumn{8}{|l|}{ Level of education } \\
\hline primary school and below & 45 & $(6.7)$ & 28 & $(62.2)$ & 17 & $(37.8)$ & 0.923 \\
\hline junior high school & 172 & $(25.6)$ & 107 & $(62.2)$ & 65 & $(37.8)$ & \\
\hline high school & 358 & $(53.2)$ & 232 & $(64.8)$ & 126 & $(35.2)$ & \\
\hline bachelor degree or above & 98 & $(14.6)$ & 61 & $(62.2)$ & 37 & $(37.8)$ & \\
\hline \multicolumn{8}{|l|}{ Professional types } \\
\hline business or service industries & 140 & $(20.8)$ & 82 & $(58.6)$ & 58 & $(41.4)$ & 0.635 \\
\hline government or public institution & 79 & $(11.7)$ & 52 & $(65.8)$ & 27 & $(34.2)$ & \\
\hline professional technician & 109 & $(16.2)$ & 72 & $(66.1)$ & 37 & $(33.9)$ & \\
\hline agriculture or other industries & 57 & $(8.5)$ & 39 & $(68.4)$ & 18 & $(31.6)$ & \\
\hline retirement & 288 & $(42.8)$ & 183 & $(63.5)$ & 105 & $(36.5)$ & \\
\hline \multicolumn{8}{|l|}{ Monthly income level (yuan) } \\
\hline $0 \sim$ & 76 & $(11.3)$ & 41 & $(53.9)$ & 35 & $(46.1)$ & 0.016 \\
\hline $2001 \sim$ & 271 & $(40.3)$ & 165 & $(60.9)$ & 106 & $(39.1)$ & \\
\hline 4001 & 154 & $(22.9)$ & 107 & $(69.5)$ & 47 & $(30.5)$ & \\
\hline $6001 \sim$ & 66 & $(9.8)$ & 39 & $(59.1)$ & 27 & $(40.9)$ & \\
\hline $8001 \sim$ & 46 & $(6.8)$ & 38 & $(82.6)$ & 8 & $(17.4)$ & \\
\hline $10001 \sim$ & 60 & (8.9) & 38 & $(63.3)$ & 22 & $(36.7)$ & \\
\hline \multicolumn{8}{|l|}{ self-rated health status } \\
\hline very good & 59 & (8.8) & 35 & $(59.3)$ & 24 & $(40.7)$ & 0.625 \\
\hline good & 268 & $(39.8)$ & 165 & $(61.6)$ & 103 & $(38.4)$ & \\
\hline average & 297 & $(44.1)$ & 194 & $(65.3)$ & 103 & $(34.7)$ & \\
\hline poor & 43 & $(6.4)$ & 29 & $(67.4)$ & 14 & $(32.6)$ & \\
\hline very poor & 6 & $(0.9)$ & 5 & (83.3) & 1 & $(16.7)$ & \\
\hline
\end{tabular}




\begin{tabular}{|cccccccc|}
\hline Tobacco use status & & & & & & & \\
\hline Age of start smoking & 334 & $(49.6)$ & 210 & $(62.9)$ & 124 & $(37.1)$ & 0.054 \\
\hline$\sim 19$ & 259 & $(38.5)$ & 176 & $(68.0)$ & 83 & $(32.0)$ & \\
\hline $20 \sim$ & 47 & $(7.0)$ & 27 & $(57.4)$ & 20 & $(42.6)$ & \\
\hline $30 \sim$ & 33 & $(4.9)$ & 15 & $(45.5)$ & 18 & $(54.5)$ & \\
\hline $40 \sim$ & & & & & & & \\
\hline Smoking age (years) & 28 & $(4.2)$ & 16 & $(57.1)$ & 12 & $(42.9)$ & 0.515 \\
\hline$\sim 9$ & 91 & $(13.5)$ & 56 & $(61.5)$ & 35 & $(38.5)$ & \\
\hline $10 \sim$ & 116 & $(17.2)$ & 72 & $(62.1)$ & 44 & $(37.9)$ & \\
\hline $20 \sim$ & 148 & $(22.0)$ & 103 & $(69.6)$ & 45 & $(30.4)$ & \\
\hline $30 \sim$ & 290 & $(43.1)$ & 181 & $(62.4)$ & 109 & $(37.6)$ & \\
\hline $40 \sim$ & & & & & & & \\
\hline Nicotine dependence levelWFTNDV & 188 & $(27.9)$ & 125 & $(66.5)$ & 63 & $(33.5)$ & 0.528 \\
\hline very low & 152 & $(22.6)$ & 99 & $(65.1)$ & 53 & $(34.9)$ & \\
\hline low & 114 & $(16.9)$ & 74 & $(64.9)$ & 40 & $(35.1)$ & \\
\hline moderate & 159 & $(23.6)$ & 92 & $(57.9)$ & 67 & $(42.1)$ & \\
\hline high & 60 & $(9.0)$ & 38 & $(63.3)$ & 22 & $(36.7)$ & \\
\hline very high & & & & & & & \\
\hline
\end{tabular}

Table2 The attempts behaviors of respondents in the study who had ever tried to quit smoking $\square \mathrm{n}=428 \square$ 


\begin{tabular}{|c|c|c|}
\hline Attempts of smoking cessation & No. & $\%$ \\
\hline \multicolumn{3}{|l|}{ Times of attempts to quit smoking } \\
\hline only 1 time & 146 & 34.1 \\
\hline 2 times & 133 & 31.1 \\
\hline 3 times & 87 & 20.3 \\
\hline 4 times or more & 62 & 14.5 \\
\hline \multicolumn{3}{|l|}{ Duration of cessation the last time } \\
\hline less than 1 day & 30 & 7.0 \\
\hline 1-7 days & 116 & 27.1 \\
\hline 8-30 days & 81 & 18.9 \\
\hline more than a month & 113 & 26.4 \\
\hline more than half a year & 88 & 20.6 \\
\hline \multicolumn{3}{|l|}{ The last time of quitting smoking } \\
\hline within the last 30 days & 40 & 9.3 \\
\hline within $1-6$ months & 64 & 15.0 \\
\hline within 7 to 12 months & 25 & 5.8 \\
\hline a year ago $\mathbb{Z}$ & 299 & 69.9 \\
\hline \multicolumn{3}{|l|}{ Methods of smoking cessation ${ }^{a}$} \\
\hline nicotine replacement therapy & 19 & 4.4 \\
\hline consulting & 30 & 7.0 \\
\hline other western medicine & 12 & 2.8 \\
\hline Chinese herbal medicine and acupuncture & 6 & 1.4 \\
\hline tobacco quit line & 3 & 0.7 \\
\hline smokeless tobacco products & 14 & 3.3 \\
\hline electronic cigarettes & 90 & 21.0 \\
\hline nothing except self-control & 337 & 78.7 \\
\hline others & 18 & 4.2 \\
\hline \multicolumn{3}{|l|}{ Reasons for failure to quit smoking ${ }^{a}$} \\
\hline lack of self-control and personal perseverance & 241 & 56.3 \\
\hline lack of professional guidance & 89 & 20.8 \\
\hline lack of concern and understanding & 18 & 4.2 \\
\hline lack of a smoke-free supportive environment & 113 & 26.4 \\
\hline lack of supporting information & 53 & 12.4 \\
\hline nervous, anxious or depressed & 71 & 16.6 \\
\hline weight gain & 9 & 2.1 \\
\hline work or study stress & 68 & 15.9 \\
\hline
\end{tabular}

Page $11 / 13$ 
Table 3 Differences in RRSQ scores among participants with different attempts behaviors

\begin{tabular}{|c|c|c|c|c|c|c|c|c|c|}
\hline \multirow{2}{*}{$\begin{array}{l}\text { Scores of } \\
\text { each } \\
\text { dimension } \\
\text { and factor in } \\
\text { the RRSQ } \\
\text { scale }^{\text {a }}\end{array}$} & \multicolumn{2}{|c|}{$\begin{array}{l}\text { Whether had Smoking } \\
\text { cessation attempts or not } \\
\square n=673 \square\end{array}$} & \multirow[t]{2}{*}{$F 1$} & \multicolumn{5}{|c|}{ Duration of cessation $\square n=428 \square$} & \multirow[t]{2}{*}{$F 2$} \\
\hline & YES & NO & & $\begin{array}{l}\text { less than } 1 \\
\text { day }\end{array}$ & 1-7 days & 8-30 days & 1-6 months & $\begin{array}{l}\text { more than } \\
\text { half a year }\end{array}$ & \\
\hline $\begin{array}{l}\text { psychological } \\
\text { image }\end{array}$ & $3.79 \pm 0.14$ & $3.75 \pm 0.18$ & 0.121 & $3.62 \pm 0.5$ & $3.89 \pm 0.29$ & $3.93 \pm 0.41$ & $3.73 \pm 0.27$ & $3.64 \pm 0.26$ & 0.643 \\
\hline $\begin{array}{l}\text { hand mouth } \\
\text { activity }\end{array}$ & $4.79 \pm 0.19$ & $4.65 \pm 0.24$ & 0.826 & $5.27 \pm 0.64$ & $5.25 \pm 0.4$ & $4.62 \pm 0.42$ & $4.6 \pm 0.37$ & $4.41 \pm 0.37$ & $3.215^{\star}$ \\
\hline indulgent & $6.83 \pm 0.21$ & $6.57 \pm 0.28$ & 2.228 & $7.5 \pm 0.92$ & $7.39 \pm 0.43$ & $6.93 \pm 0.48$ & $6.39 \pm 0.41$ & $6.41 \pm 0.43$ & $4.424^{\star}$ \\
\hline sedative & $6.9 \pm 0.24$ & $6.16 \pm 0.29$ & $14.509 * \star$ & $7.92 \pm 1.00$ & $7.37 \pm 0.48$ & $7.3 \pm 0.48$ & $6.58 \pm 0.46$ & $5.95 \pm 0.48$ & $6.642^{\star *}$ \\
\hline stimulation & $6.32 \pm 0.24$ & $5.77 \pm 0.29$ & $7.945^{\star}$ & $7.65 \pm 1.03$ & $6.81 \pm 0.5$ & $6.19 \pm 0.53$ & $6 \pm 0.47$ & $5.82 \pm 0.47$ & $4.376^{\star}$ \\
\hline addictive & $5.51 \pm 0.22$ & $4.89 \pm 0.27$ & $11.636^{\star \star}$ & $6.85 \pm 0.99$ & $6.1 \pm 0.47$ & $5.3 \pm 0.49$ & $5.13 \pm 0.4$ & $5.05 \pm 0.48$ & $5.844^{\star *}$ \\
\hline automatic & $5.08 \pm 0.19$ & $4.63 \pm 0.23$ & $8.217^{*}$ & $5.46 \pm 0.69$ & $5.37 \pm 0.4$ & $4.86 \pm 0.47$ & $4.95 \pm 0.34$ & $4.82 \pm 0.44$ & 1.504 \\
\hline $\begin{array}{l}\text { auxiliary } \\
\text { scale }\end{array}$ & $6.1 \pm 0.21$ & $5.8 \pm 0.27$ & 2.843 & $6.69 \pm 0.80$ & $6.81 \pm 0.44$ & $6.27 \pm 0.46$ & $5.54 \pm 0.42$ & $5.55 \pm 0.43$ & $6.852^{\star \star \star}$ \\
\hline $\begin{array}{l}\text { Social- } \\
\text { psychological }\end{array}$ & $15.42 \pm 0.41$ & $14.97 \pm 0.53$ & 1.702 & $16.38 \pm 1.35$ & $16.54 \pm 0.87$ & $15.47 \pm 0.99$ & $14.73 \pm 0.82$ & $14.45 \pm 0.78$ & $4.089 *$ \\
\hline $\begin{array}{l}\text { Dependence } \\
\text { and Addiction }\end{array}$ & $29.91 \pm 0.84$ & $27.25 \pm 1.04$ & $14.694^{\star \star}$ & $34.58 \pm 2.91$ & $32.45 \pm 1.79$ & $29.91 \pm 1.8$ & $28.19 \pm 1.61$ & $27.18 \pm 1.75$ & $7.598^{\star \star *}$ \\
\hline
\end{tabular}

a Data are mean $\pm S D \rrbracket * p<0.05 . \quad$ ** $p<0.001$

Table 4 Regression relationship between smoking reasons and Smoking cessation attempts

\begin{tabular}{|c|c|c|c|c|}
\hline \multirow[t]{2}{*}{ FACTORS of RRSQ } & \multicolumn{2}{|c|}{ Whether had Smoking cessation attempts or not $\varangle n=673 \rrbracket$} & \multicolumn{2}{|c|}{ Duration of cessation $₫ n=428 \rrbracket$} \\
\hline & OR (95\% C.I.) & Pvalue & OR (95\% C.I.) & $P$ value \\
\hline \multicolumn{5}{|l|}{ Social-psychological } \\
\hline psychological image & $0.941(0.828 \sim 1.071)$ & 0.358 & $1.079(0.946 \sim 1.230)$ & 0.259 \\
\hline hand mouth activity & $0.929(0.828 \sim 1.042)$ & 0.206 & $0.955(0.851 \sim 1.073)$ & 0.438 \\
\hline indulgent & $0.973(0.879 \sim 1.076)$ & 0.592 & 0.984(0.887 1.092) & 0.762 \\
\hline \multicolumn{5}{|l|}{ Dependence and Addiction } \\
\hline sedative & $1.111(1.011 \sim 1.220)$ & 0.028 & $0.911(0.827 \sim 1.002)$ & 0.045 \\
\hline stimulation & $1.034(0.944 \sim 1.133)$ & 0.473 & 0.972(0.888 1.064) & 0.541 \\
\hline addictive & $1.152(1.034 \sim 1.282)$ & 0.010 & $0.919(0.827 \sim 1.021)$ & 0.115 \\
\hline automatic & $1.119(1.000 \sim 1.251)$ & 0.049 & $1.056(0.947 \sim 1.177)$ & 0.326 \\
\hline auxiliary scale & $0.939(0.839 \sim 1.052)$ & 0.276 & 0.935(0.833 1.049) & 0.251 \\
\hline
\end{tabular}

Note: :Yes $=1 ;$ No=0(Reference); lless than 1 day=1; $1-7$ days=2; 8-30 days=3; $1-6$ months=4; more than half a year=5 (Reference);Monthly income was incorporated into the model as covariables, $\mathrm{P} 1=0.102, \mathrm{P} 2=0.160$, and the regression coefficient was not statistically significant, 


\section{Figures}

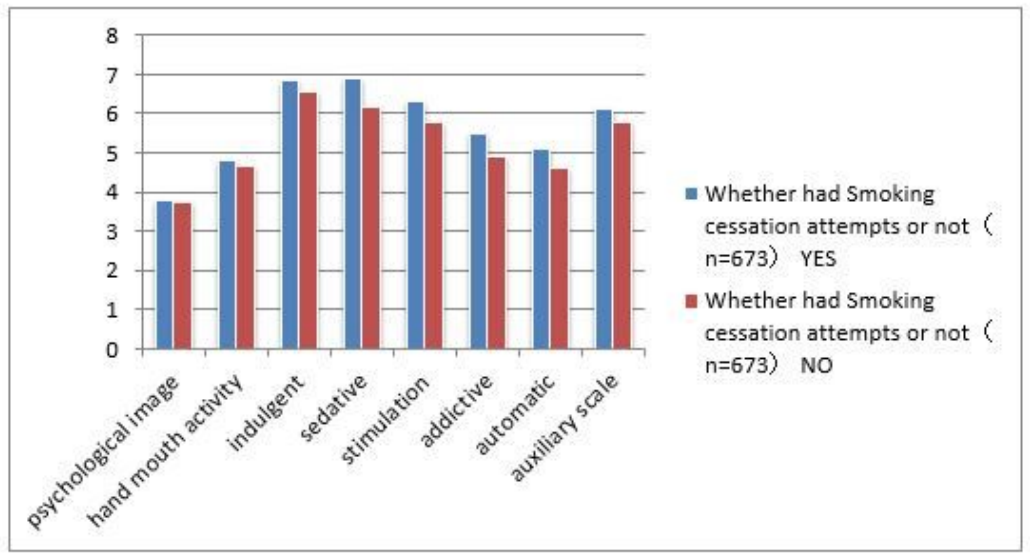

Figure 1

Differences in RRSQ scores among participants who had Smoking cessation attempts and those who had not

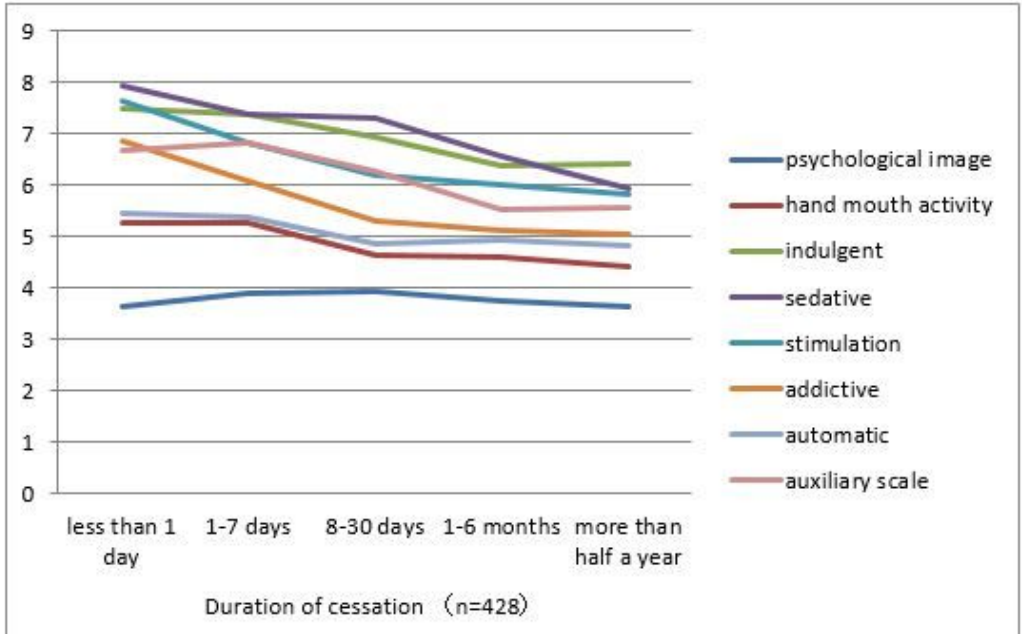

Figure 2

Differences in RRSQ scores among participants with different duration of cessation 